\title{
50 años de orgullo. Un repaso escrito y visual por la historia del movimiento LGTBIQ+ ${ }^{1}$ en España
}

\section{0 years of pride. A written and visual review of the history of the LGTBIQ+ movement in Spain}

\author{
Rafael VILLENA ESPINOSA \\ Universidad de Castilla-La Mancha \\ rafael.vespinosa@uclm.es
}

"La gran revolución es la revolución trans" (Paco Tomás, guionista de televisión)

"Algunos pensarán que no va con ellos. Se equivocan.

Esta historia es la de todos" (Alberto Mira, profesor universitario)

\section{RESUMEN}

En 1970 se aprobaba en España la Ley de Peligrosidad Social que condenaba penalmente las relaciones homosexuales. Ese mismo año, en diversas ciudades de Estados Unidos, se celebraban las primeras marchas del orgullo en recuerdo de la revuelta de Stonewall (1969), que tardarían siete años en encontrar su réplica en nuestro país (Barcelona, 1977). Así, 2017, 2019, 2020 son fechas en las que resuenan décadas de lucha en la historia del activismo LGTBIQ+. A propósito de tales conmemoraciones, se propone un balance historiográfico con las aportaciones recientes más significativas, un estado de la cuestión en el que debe incluirse también la serie de televisión Nosotrxs somos como relato visual histórico de ese nuevo movimiento social.

Palabras clave: Historiografía, LGTBIQ+, giro queer, nuevos movimientos sociales, Transición democrática

Topónimo: España

Período: siglo XX, siglo XXI

1 Siglas que emplearé para referirme al movimiento. Se conoce suficientemente el significado de las primeras: Lesbianas, Gais, Transexuales y Bisexuales. Quizás no tanto la "I", que alude a las personas nacidas con rasgos difícilmente identificables con el género masculino o femenino y son, pues, intersexuales. Naciones Unidas estima que afecta a un $1^{\prime} 7 \%$ de los bebés, sometidos en muchos países a cirugías irreversibles. https://www.unfe.org/es/intersex-awareness/. La "Q" incluye al sector más radical del movimiento, amagado bajo la teoría queer, pero también se refiere a questioning, es decir, a aquellas personas que no desean ser etiquetadas bajo la pauta binaria del género. Finalmente, el signo "+" abraza otras fórmulas de subjetividad como la asexualidad o la pansexualidad. Una explicación sencilla en https://www.lavanguardia.com/vida/ junior-report/20190627/463124839887//gbtiq-definiciones.html y de manera visual en https://elpais.com/ especiales/2019/diccionario-diversidad-sexual/. 


\section{ABSTRACT}

In 1970, the Law on Social Danger and Rehabilitation was passed in Spain, legislation that made homosexual relations a criminal offence. In the same year, in various cities in the United States, the first pride parades were held in memory of the Stonewall riots (1969), which found a response in our country seven years later (Barcelona, 1977). 2017, 2019, 2020 are landmark dates in the decades of struggle in the history of LGTBIQ+ activism. With regard to these commemorations, we propose a historiographic assessment of the most significant recent contributions, a state of affairs in which the television series Nosotrxs somos, a visual historical account of this new social movement, should be also included. Transition

Key words: Historiography, LGTBIQ+, Queer Turn, New Social Movements, Democratic

Place names: Spain

Period: 20th century, 21st century

\section{HISTORIA, MEMORIA, HISTORIOGRAFÍA}

Los hechos son de sobra conocidos. Madrugada del 28 de junio de 1969, los clientes de un pequeño bar de Nueva York (Stonewall Inn), en buena medida chaperos, travestis y transexuales, se resistieron a la enésima redada de la policía, enfrentándose a los agentes que les hostigaban de manera recurrente y caprichosa. La acción derivó en altercados por las calles aledañas del Greenwich Village que se prolongaron durante tres días. Por primera vez los homosexuales desafiaban contundentemente el orden heteronormativo y su represión. Al año siguiente, una manifestación recorrió varias manzanas del barrio neoyorquino en recuerdo de aquel primer gesto de rebeldía y también hubo concentraciones en otras ciudades del país, como Los Ángeles y Chicago. Eran los orígenes de la marcha del orgullo, palabra que ya se incorporó a algunas de las pancartas, junto a lemas por la igualdad y la liberación de los gais, en un ambiente politizado que desbordaba la estrategia desarrollada en décadas anteriores por asociaciones como Mattachine Society². Estas dos fechas marcaron los hitos fundacionales del movimiento LGTBIQ+ en Estados Unidos, la construcción de un mito conmemorativo que sirvió como catalizador para asociaciones preexistentes, a la vez que concitó nuevas adhesiones ${ }^{3}$.

En España, la primera manifestación a favor de los derechos de los homosexuales tuvo lugar en Barcelona el 26 de junio de 1977. Unas cuatro mil personas, encabezadas, nuevamente, por travestis y transexuales, marcharon por Las Ramblas coreando lemas contra la represión hasta que fueron disueltas violentamente por la policía. La manifestación ha quedado en la historia del movimiento como su momento fundacional, una suerte de Stonewall español. Detrás estaba el FAGC (Front d'Alliberament Gai de Catalunya),

2 Existía activismo y hubo conflictos antes de Stonewall, habitualmente ligados a espacios de sociabilidad. Recordemos: Los Ángeles 1959 y 1967, Filadelfia 1965, Nueva York 1966 y San Francisco 1966. Ver E. A. Armstrong, Fording gay identities: Organizing sexuality in San Francisco, 1950-1994, Chicago, Chicago University Press, 2002, 290 pp.; V. L. Bullough (ed.), Before Stonewall: Activists for Gay and Lesbian Rights in Historical Context, New York, Routledge, 2008, .mobi; L. Faderman, The Gay Revolution: The Story of the Struggle, New York, Simon \& Schuster, 2015, .mobi; J. Sears, Behind the Mask of the Mattachine: The Hal Call Chronicles and the Early Movement for Homosexual Emancipation, New York, Routledge, 2011, .mobi; y M. Stein, City Of Sisterly And Brotherly Loves: Lesbian And Gay Philadelphia, 1945-1972, Filadelfia, Temple University Press, 2004, 461 pp.

3 E. A. Armstrong y S. M. Crage, "Movements and Memory: The Making of the Stonewall Myth", American Sociological Review, 71 (2006), pp. 724-751. 
asociación impulsada en 1975 por Armand de Fluviá, quien, años antes de morir el dictador, ya había iniciado su particular lucha contra la homofobia estatal del franquismo. En 1970, a propósito de la tramitación de la Ley de Peligrosidad y Rehabilitación Social, que suponía una clara estigmatización jurídica del homosexual, organizó junto a Francesc Francino la Agrupación Homófila para la Igualdad Sexual y promovió diversos escritos críticos contra la Ley. Esta primera red dio paso en 1971 al Movimiento Español de Liberación Homosexual, grupo clandestino que emulaba al Gay Liberation Front estadounidense ${ }^{4}$.

Así pues, estamos a medio siglo de un inicio, o a cuarenta años si nos fijamos en la manifestación de Barcelona. ¿Han tenido tales conmemoraciones algún impacto en la historiografía reciente de nuestro país? Los historiadores somos dados a los aniversarios, también las instituciones y los colectivos que amarran de ese modo nudos en su memoria a la vez que proyectan sus logros exteriormente ${ }^{5}$.

Un primer espacio que podemos rastrear es el de las exposiciones cuyo sentido ha sido recordar estas décadas de movilización social sirviéndose de un discurso en gran medida histórico. En 2017 hay que referirse a tres muestras. El Ayuntamiento de Barcelona apostaba por una instalación fotográfica en la plaza Reial, a cargo de Ricard Martínez. "Molt amor per fer" va más allá de la manifestación de 1977 e incorpora imágenes posteriores para transmitir "el relato del extraordinario esfuerzo empleado para conquistar algo muy íntimo", según su creador6. En Madrid, convivieron dos exposiciones entre el verano y el otoño de 2017. La del palacio de Cibeles llevaba el rotundo título de "Subversivas. 40 años de activismo LGTB en España". Organizada por la Federación Estatal de Lesbianas, Gais, Transexuales y Bisexuales (FELGTB), proponía un eficaz recorrido expositivo histórico hasta $2017^{7}$. Más próximo a los planteamientos queer se encontraba el ambicioso programa organizado por el Ayuntamiento de Madrid "El porvenir de la revuelta. Memoria y deseo LGTBIQ", bajo la dirección artística de Fefa Vila y que caminaba entre lo performativo y lo cronológico, al bucear en el pasado y recuperar piezas de dos décadas de expresión disidente. La exposición se desplegó en varios espacios como el centro cultural Conde Duque, entre abril y octubre ${ }^{8}$.

Al año siguiente, el Museo Nacional Centro de Arte Reina Sofía promovió una semana del orgullo, con varias actividades, entre ellas un itinerario LGTBIQ+ por la colección y la

4 J. M. Monferrer, "La construcción de la protesta en el movimiento gay español: la Ley de Peligrosidad Social (1970) como factor precipitante de la acción colectiva", Reis: Revista española de investigaciones sociológicas, 102 (2003), pp. 171-204.

5 La manifestación estatal del orgullo 2017 en Madrid recordaba esos cuarenta años de movilización y coincidía con la celebración, por primera vez en España, del World Gay Pride, una convocatoria promovida por Interpride en la que participaron más de dos millones de personas. "Mayores sin armarios. ¡Historia, lucha y memoria!" fue el lema de la manifestación de 2019, una referencia a aquellas primeras generaciones de activistas. Ver https://www.elmundo.es/madrid/2017/07/07/595f752eca4741976d8b45c7.html y https://www. abc.es/espana/abci-mayores-sin-armarios-lema-orgullo-2019-201907061548_video.html (Consulta: 20-122019. Todos los enlaces web referenciados en este texto estaban accesibles en enero de 2020, por lo que se obvia indicar la fecha de consulta en cada uno)

6 https://www.arqueologiadelpuntdevista.org/instalaciones/molt-amor-per-fer/y https://ajuntament.barcelona. cat/premsa/2017/06/16/barcelona-commemora-el-40-aniversari-de-la-primera-manifestacio-lgtbi-a-la-ciutatamb-un-programa-anual-dactivitats/.

7 Su web sigue activa, aunque con problemas de navegabilidad. https://www.felgtb.com/subversivas/exposicion/. El folleto en https://static.arteinformado.com/resources/app/docs/evento/81/141081/subversivas.pdf.

8 Merece la pena leer la entrevista de Javier Díaz-Guardiola a la comisaria, Fefa Vila, en $A B C$. https:// www.abc.es/cultura/cultural/abci-porvenir-revuelta-urgente-necesidad-social-echar-mirada-cuarenta-anosatras-201705262129_noticia.html. El programa en https://www.condeduquemadrid.es/sites/default/files/ import/activities/2017/05/el-porvenir-de-la-revuelta-dossier_abril_2017.pdf. 
reactivación de su proyecto sobre el archivo queer, lanzado en $2012^{9}$. Podemos continuar este recorrido por el madrileño Museo La Neomudéjar, en cuyas paredes se colgó "Destape y Orgullo" (junio a septiembre de 2019), un alarde de documentación visual y hemerográfica fundamental para entender las identidades homosexuales entre 1970 y 1985, lo que incluye -y ahí radicaba uno de sus atractivos - la estética erótica que llegó al mundo gay de la mano del "destape" (la revista Party se instaló en el imaginario oculto de muchos jóvenes). Finalmente, desde el ámbito universitario también se ha contribuido a la difusión de la historia del movimiento. "Un orgullo necesario. Algunos hitos históricos contra la homofobia" proponía en la Facultad de Humanidades de Toledo (UCLM), un breve itinerario por momentos de expansión y represión de una lucha que arrancaba en el siglo XIX y llega hasta los retos actuales de la persecución en más de setenta estados ${ }^{10}$.

En estos canales expositivos ${ }^{11}$, al igual que en los reportajes que algunos medios escritos dedicaron al 50 aniversario de Stonewall (El País, El Periódico o Vogue ${ }^{12}$ ), resuenan los contornos de la memoria histórica, no solo por la gramática memorialista que ha ido elaborando el colectivo como tal, sino también por la memoria singular de las personas LGTBIQ+ en la medida que víctimas de la represión. Parece difícil, pues, sustraerse a uno de los grandes debates políticos y del quehacer historiográfico actual, aunque no incidiré en ello específicamente ${ }^{13}$.

El otro gran ámbito a través del cual podríamos percibir la repercusión de estas décadas de movilización es el bibliográfico. En los últimos años se han publicado algunas aportaciones valiosas que merece la pena destacar. Son al menos cinco libros que demuestran el grado de madurez al que se encaminan los estudios LGTBIQ+ y que recogen una trayectoria anterior por la que debo empezar ${ }^{14}$. Así, al iniciarse el siglo XXI habían visto la luz dos trabajos centrados en la represión franquista: Redada de violetas, de Arturo Arnalte (2003), y El látigo y la pluma de Fernando Olmeda (2004); ambos subrayaron la crueldad del

9 https://www.museoreinasofia.es/actividades/sexualidad-libre y https://www.museoreinasofia.es/actividades/ archivo-queer-memoria-disidente.

10 La muestra estaba organizada por el Centro de Estudios de Castilla-La Mancha y la Facultad de Humanidades de Toledo (UCLM), con el comisariado de Rafael Villena y Esther Almarcha. Después de la Facultad, ha pasado por el Centro Cultural de San Marcos (Toledo) y diversos centros de enseñanza secundaria entre el otoño de 2019 y enero de 2020, como el IES Lazarillo de Tormes de Escalona (Toledo) y la Escuela de Arte Pedro Almodóvar de Ciudad Real. Ver https://humanidadestoledo.uclm.es/exposicionun-orgullo-necesario-algunos-hitos-historicos-contra-la-homofobia/, https://www.latribunadetoledo.es/Noticia/ Z55F73E58-FB16-9A43-FAFD19A99C23A2E0/201905/Un-Orgullo-necesario y https://blog.uclm.es/cic/ agenda/un-orgullo-necesario/. El catálogo expositivo en torno a la celebración del orgullo es mayor del que aquí se menciona.

11 Sin querer establecer comparaciones valorativas, creo que un referente internacional fue el extenso programa organizado por la New York Public Library, incluida una exposición. Ver https://www.nypl.org/ stonewall50.

12 https://elpais.com/tag/orgullo_gay/a, https://www.elperiodico.com/es/mas-periodico/20190622/50-anosde-stonewall-el-dia-que-nacio-el-gay-power-7514741, https://www.vogue.es/living/articulos/stonewall-50aniversario-lucha-Igtb.

13 Ver, entre otros muchos, J. Cuesta (ed.), "Memoria e Historia", dosier monográfico de Ayer, 32 (1998), pp. 11-245; S. Gálvez (coord.), "Generaciones y memoria de la represión franquista: un balance de los movimientos por la memoria", Hispania Nova, 7 (2007), sp. http://hispanianova.rediris.es/7/dossier.htm; J. S. Pérez Garzón, "Memoria e historia: reajustes y entendimientos críticos", Ayer, 86 (2012), pp. 249-261.

14 Estas páginas versan sobre la historia del movimiento LGTBIQ+ en España, pero no abordan la multitud de debates y cuestiones problematizadas que se han planteado sobre las identidades y, por lo tanto, no se recogen estudios publicados desde otras ramas del saber sobre homonormativización, biopolítica o guetización. 
sistema carcelario y reivindicaron la memoria de un grupo casi invisible en otros estudios ${ }^{15}$. El de Arnalte, construido con mayor rigor historiográfico, mientras que Olmeda no evita la impronta periodística en el tratamiento de ciertas cuestiones. Por las mismas fechas aparecieron dos libros de Jordi Petit que proyectan su experiencia desde el epicentro de la movilización. Uno, de carácter analítico y colectivo; el segundo más subjetivo y emocional ${ }^{16}$. Igualmente, Armand de Fluviá lanzaba su análisis sobre el movimiento gay en la Cataluña del tardofranquismo ${ }^{17}$. Durante esta suerte de bienio prodigioso, editorialmente hablando, Alberto Mira publicó De Sodoma a Chueca, un texto que constituye una apretada historia cultural de la homosexualidad en el siglo $X X$ y que pronto se convirtió en un referente ineludible ${ }^{18}$. Mira cubre en su ambiciosa obra multitud de hechos culturales, partiendo de la configuración del concepto de homosexual como categoría científica hasta el fenómeno del barrio gay de Chueca a principios de los noventa.

Figura 1. Manifestación en Barcelona, 25 de junio de 1978. Como en el año anterior, convocó el FAGC. También hubo manifestaciones, por primera vez, en Madrid, Sevilla y Valencia.

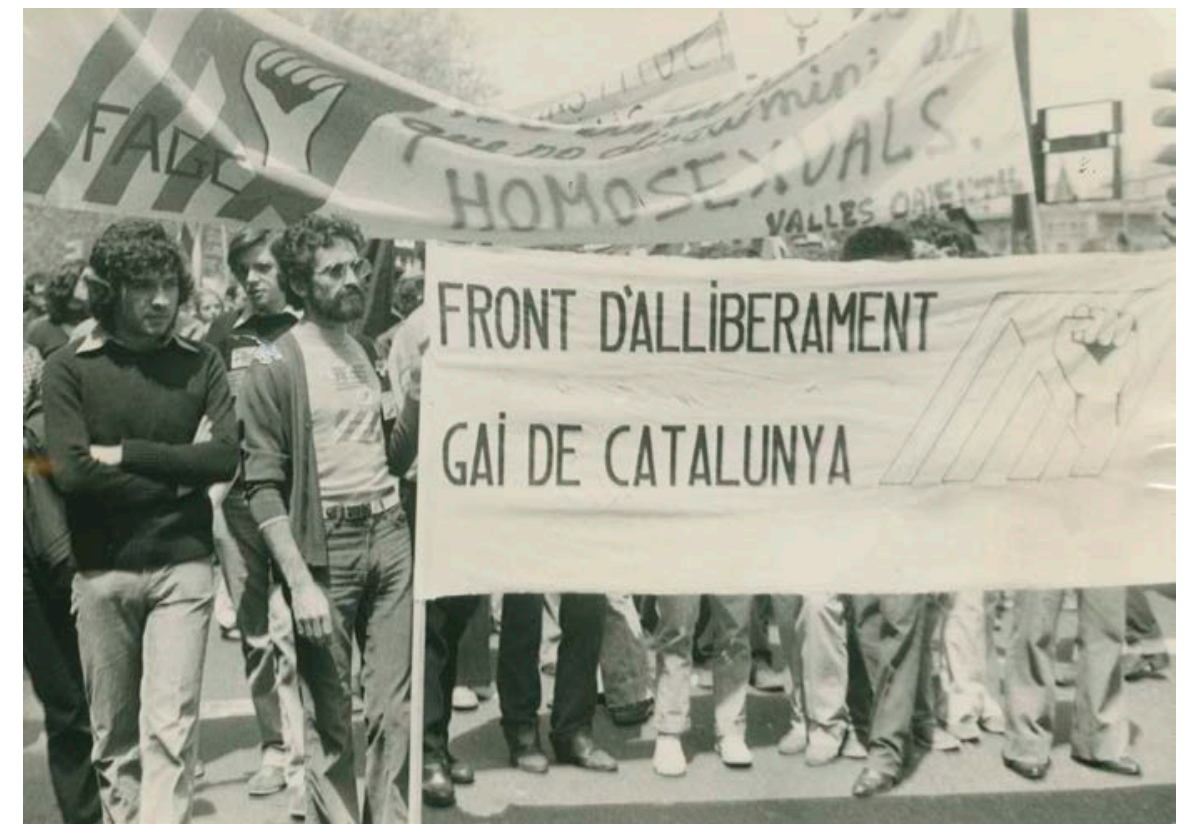

Fuente: Arxiu Fotogràfic de Barcelona, fondo Diari de Barcelona, sin autor

El franquismo y la Transición han continuado atrayendo el interés de los expertos en años posteriores. Así lo corroboran el libro de Manuel Soriano desde una perspectiva psicológica sobre la marginación impuesta a los homosexuales (2006), el opúsculo de

15 A. Arnalte, Redada de violetas: la represión de los homosexuales durante el franquismo, Madrid, La Esfera de los Libros, 2003, 303 pp. y F. Olmeda, El látigo y la pluma: homosexuales en la España de Franco, Madrid, Oberón, 2004, 339 pp. Ver S. Frouz, "Una historia propia: la memoria homosexual en España", Journal of Iberian and Latin American Studies, 13, 1 (2007), pp. 97-103.

16 J. Petit, 25 años más: una perspectiva sobre el pasado, el presente y futuro del movimiento de gays, lesbianas, bisexuales y transexuales, Barcelona, Icaria, 2003, 293 pp. y Vidas del arco iris: historias del ambiente, Barcelona, De Bolsillo, 2004, 267 pp.

17 A. de Fluviá, El moviment gai a la clandestinitat del franquisme (1970-1975), Barcelona, Laertes, 2003, $278 \mathrm{pp}$.

18 A. Mira, De Sodoma a Chueca: una historia cultural de la homosexualidad en España en el siglo XX, Barcelona-Madrid, Egales, 2004, 636 pp. Previamente publicó Para entendernos: diccionario de cultura homosexual, gay y lésbica, Barcelona, Ediciones de la Tempestad, 1999, 777 pp. 
Nathan Baidez que confronta las dos principales leyes represivas del franquismo (2007), el colectivo coordinado por Javier Ugarte (2008) que recoge testimonios vividos en las cárceles e indaga en la criminalización de la homosexualidad, y, más recientemente (2016), el enfoque desde la literatura pedagógica de Víctor Mora ${ }^{19}$. Pero, sobre todo, interesa destacar la irrupción de las lesbianas en el mapa historiográfico, singularmente gracias al libro de la socióloga Gracia Trujillo, Deseo y resistencia (2009), un exhaustivo recorrido por la historia de la autoconciencia lésbica entre 1977 y 2007. Treinta años de lucha por la visibilidad enramados en tres olas, como las define la autora, que pueden contrastarse con el trabajo de Raquel Osborne, en el contexto más amplio del feminismo español ${ }^{20}$.

Ya en la segunda década del siglo XXI se dieron nuevos pasos en la consolidación historiográfica. Merece la pena leer Los invisibles (Richard Cleminson y Francisco Vázquez, 2011) porque abre un período poco transitado (1850-1939) a partir del estudio del discurso legal, médico y pedagógico. Las influencias foucaultianas son claras, mas el trabajo matiza al filósofo francés al concebir la homosexualidad no como el resultado de una construcción en discurso lineal, sino como la "coexistencia de figuras nuevas y antiguas, de viejos y nuevos modelos de subjetividad, en muchos ámbitos de la historia de España"21. Puede que la obra no resuelva todas las líneas posibles como reconocen los autores, pero resulta fundamental para entender la genética de una categoría social y jurídica que ha marcado la discriminación de tantos individuos. Vázquez fue también el coordinador del número que la revista Ayer dedicó a las homosexualidades en 2012. Un dosier que no gira en sentido estricto sobre el movimiento, pero con aportaciones que resultan clarificadoras todavía hoy ${ }^{22}$. Uno de sus autores, Geoffroy Huard, es quien ha abierto de una manera clara la perspectiva internacional con su Historia de la homosexualidad en Barcelona y París, 1945-1975; y no solo, ya que ha cuestionado el relato tradicional sobre la existencia de un único punto germinal para entender la resistencia gay en ambos países. Igualmente, su investigación, que ha tenido continuidad editorial en Les gays sous le franquisme ${ }^{23}$, desmonta la percepción apriorística de una mayor represión en Francia, cuando su policía fue muy activa en la detención de homosexuales. Ambos textos se apoyan en una vasta documentación que le ha permitido transitar por las subculturas gais, los lugares de encuentro sexual, así como desvelar una solidaridad homófila entre el minúsculo movimiento español y Arcadie. Hay, pues, una prehistoria que el autor rescata y que considera igual de revolucionaria.

19 M. A. Soriano, La marginación homosexual en la España de la Transición, Barcelona-Madrid, Egales, 2006, 228 pp.; N. Baidez, Vagos, maleantes... y homosexuales: la represión a los homosexuales durante el franquismo, Barcelona, Malhivern, 2007, 93 pp.; y F. J. Ugarte (ed.), Una discriminación universal: la homosexualidad bajo el franquismo y la Transición, Bacelona-Madrid, Egales, 2008, 273 pp. En 2005 salió en la misma editorial Sin derramamiento de sangre. Un ensayo sobre la homosexualidad, 152 pp. Este especialista en Foucault puso en marcha Orientaciones. Revista de homosexualidades, una publicación científica editada por la Fundación Triángulo que sacó once números (2001-2006). También V. Mora, Al margen de la naturaleza. La persecución de la homosexualidad durante el franquismo. Leyes, terapias y condenas, Barcelona, Debate, 2016, 222 pp.

20 R. Osborne (ed.), Mujeres bajo sospecha. Memoria y sexualidad, 1930-1980, Madrid, Editorial Fundamentos, 2012, 419 pp.

21 Ibídem, p. 11.

22 F. Vázquez (coord.), "Homosexualidades", dosier de Ayer, 87 (2012), 130 pp.

23 G. Huard, Los antisociales, Historia de la homosexualidad en Barcelona y París, 1945-1975, Madrid, Marcial Pons, 2014, 381 pp. y Les gays sous le franquisme. Discours, subcultures et revendications à Barcelone, 1939-1977, Paris, Éditions Orbis Terrius, 2016, 314 pp. Casi la mitad de las páginas están dedicadas a reproducir documentación. 
Llegamos en este estado de la cuestión a los años más cercanos (2017-2019), en los que, como decía al principio, han venido a coincidir el recuerdo de lo que sucedió en Barcelona y Nueva York con aportaciones relevantes sobre la cuestión gay. Los trabajos científicos son imprescindibles para el avance del saber, pero también es importante la divulgación, si no queremos quedarnos encapsulados en la academia y en los círculos endogámicos de lectura. Esa función la ha cumplido el libro Lo nuestro sí que es mundial, firmado por Ramón Martínez, filólogo de formación (lo cual debería mover, quizás, a cierta reflexión entre los historiadores) ${ }^{24}$. El libro arranca con un liviano recorrido por las primeras voces que abordaron la cuestión homosexual desde la Antigüedad, pero sobre todo desde la Ilustración y el siglo XIX. El grueso de la obra se divide en dos capítulos que constituyen un excelente trabajo de síntesis, clarificación y difusión de la genealogía del movimiento en nuestro país, con sus conflictos internos, escisiones, y momentos de zozobra. Martínez nos guía, a veces con excesivo apego a la fecha, por los nervios del fenómeno asociativo, estrategias reivindicativas y renovación en el liderazgo. Incluso, se incorpora información sobre otras partes de España, más allá de la centralidad compartida de Barcelona y Madrid $^{25}$. La llegada del SIDA provocó un auténtico colapso en el colectivo, obviamente por el impacto afectivo, pero también porque le enfrentó a la necesidad de redefinir su papel público. Son páginas intensas, que demuestran el grado de torpeza con el que se actuó durante los primeros años ochenta, mientras se debatía acerca de la estigmatización sobrevenida que podría provocar cualquier campaña de prevención. Mas la pandemia tuvo efectos positivos porque de ahí surgió con fuerza la reivindicación del derecho al matrimonio, inicialmente como ley de parejas de hecho. "La batalla de los afectos" es el acertado título de un epígrafe en el que se desgrana el proceloso camino hasta 2005, liderado ya por una "tercera ola" de activistas. La última parte se abre a la diversidad trans y bisexual, no siempre suficientemente atendidas ${ }^{26}$, y concluye con un saldo claramente positivo, ayudado en su balance por el testimonio de diversos líderes del colectivo.

La historiografía se ha enriquecido en 2017 con la aportación sociológica de Kerman Calvo en ¿Revolución o reforma? ${ }^{27}$. De intensa carga teórica, sobre el pilar inicial de Charles Tilly y su categorización de los movimientos sociales (outsiders/insiders), Calvo se propone un objetivo claro: explicar por qué el movimiento LGTBIQ+ ha sido parte activa de la política, desde el momento en el que resolvió la disyuntiva de ahondar en las prácticas revolucionarias (liberacionistas) o buscar objetivos legislativos (pragmáticos). Un giro que parecía inevitable desde mediados de los ochenta y que provocó una sima generacional que el autor evita valorar desde cualquier atalaya ética ${ }^{28}$. El trabajo está rigurosamente documentado, es ajustado conceptualmente y contiene pasajes reveladores desde el punto de vista de la historia política, como los relativos a la homofobia del PSOE y del PCE en los primeros años de la Transición, situación que evolucionó más rápidamente en el caso de los comunistas con la creación de Izquierda Unida. En el espacio de las relaciones con

24 R. Martínez, Lo nuestro sí que es mundial. Una introducción a la historia del movimiento LGTB en España, Barcelona-Madrid, Egales, 2017, 346 pp. El texto forma parte de una trilogía, en la misma editorial: La cultura de la homofobia (2016, 186 pp.) y el más reciente, Nos acechan todavía. Anotaciones para reactivar el movimiento LGTB (2019, 281 pp.).

25 R. Martínez, Lo nuestro sí que es..., pp. 106 y ss.

26 Ibídem, pp. 266-275. "Diferentes caminos para un solo movimiento".

27 K. Calvo, ¿Revolución o reforma? La transformación de la identidad política del movimiento LGTB en España, 1970-2005, Madrid, CSIC, 2017, 240 pp. El trabajo, en realidad, se centra mayormente en los años 80 y 90.

28 Ibídem, caps. IV-V y p. 206. 
Ios partidos, provoca sonrojo releer algunas declaraciones de dirigentes del Partido Popular (Montoro vislumbraba en 2003 que el paro subiría si se aprobaba el matrimonio entre personas del mismo sexo) interpretadas por Calvo como una estrategia obstruccionista para "desdibujar la demanda que sustentaría la extensión de derechos civiles y otras prácticas de reconocimiento de ciudadanía"29.

En el polo opuesto a los planteamientos de Martínez y Calvo cabe situar el libro de Brice Chamouleau, Tiran al maricón ${ }^{30}$. Deudor de los resortes epistemológicos de la teoría queer, los estudios poscoloniales y la historia de los conceptos, propone una alternativa al discurso historiográfico que él clasifica como oficial, para narrar "la historia de una derrota... contrahistoria del éxito queer que viene conociendo España desde hace unos veinte años"31. Por ello, tiene el interés de visibilizar aquellas subjetividades de la homosexualidad enfrentadas a lo que se acabó imponiendo como normativo y que nos desvelan las pulsiones "plumófobas" de la sociedad española, también en el seno del movimiento LGTBIQ+. Su texto es una enmienda en toda regla, además, al modelo pactista de la Transición y desvela la política represiva contra las personas queer, especialmente de extracción social baja (el "bujarrón" de los documentos policiales), prolongada mucho más allá de la franquista Ley de Peligrosidad Social. Sólidamente documentado en fuentes judiciales y hemerográficas catalanas, queda sin embargo ensombrecido a veces por un lenguaje críptico, así como por la deriva apocalíptica a la que conducen sus conclusiones cuando proclama el derrumbe de las clases medias consumidoras o la sustitución de trabajadores por máquinas y ordenadores ${ }^{32}$. La crítica al "homonacionalismo", que ha hecho del matrimonio gay la bandera de España como democracia sexual, es tan persistente que casi pareciera preferible regresar a la distopía del tardofranquismo con tal de que nadie se apropie políticamente de las igualdades jurídicas logradas en estas décadas. Así, desde las primeras páginas del libro verbalizaba su "desconfianza hacia lo que se concibe como avances jurídicos y democráticos en materias sexuales a escala occidental"33. Con todo, es de lectura obligada si quiere comprenderse el debate historiográfico, la diversidad vivencial del movimiento y una reivindicación militante de sus memorias plurales minoritarias.

En efecto, los queer studies irrumpieron en la historiografía para denunciar el silenciamiento sobre las disidencias corporales. Era un grito desde la diversidad contra la imposición de cualquier homonormativización, conectado conceptualmente con el posfeminismo y socialmente con los grupos disidentes que tienen un buen exponente en la americana ACT UP, o en España asociaciones como La Radical Gai y Lesbianas Sin Dudas. Reivindicaron (reivindican) la acción frente a la estabilidad del paradigma familiar, la crítica social intensa frente al asimilacionismo y el descaro marica, gozosamente plumífero, frente al gay masculinizado ${ }^{34}$.

29 Ibídem, p. 211 para la cita textual y 210 para la referencia a Montoro.

30 B. Chamouleau, Tiran al maricón. Los fantasmas queer de la democracia (1970-1988), Madrid, Akal, 2017, 408 pp. Cito a partir de la edición en .epub.

31 Ibídem, Introducción.

32 Ibídem, cap. 8.

33 Ibídem, Introducción y cap. 2.

34 La teoría queer debe mucho a los textos de Teresa de Laurentis, Eve Kosofsky y Judith Butler. Para España, ver, entre otros, D. Córdoba, J. Sáez y P. Vidarte, Teoría Queer. Políticas bolleras, maricas, trans, mestizas, Barcelona-Madrid, Egales, 2005, 257 pp.; L. Posada, "Teoría queer", Daimon. Revista Internacional de Filosofía, 63 (2014), pp. 147-158; L. Vélez-Pelligrini, Sujetos de un contradiscurso. Una historia intelectual de la producción teórica gay, lesbiana y queer en España, Barcelona, Ediciones Bellaterra, 2011,319 pp. 
Procedente de la militancia anticapitalista y en confluencia con lo queer, aunque sin el barroquismo conceptual de otros autores, cabría situar el extensísimo volumen de Piro Subrat titulado Invertidos y rompepatrias ${ }^{35}$. Podría decirse que se trata de una obra en construcción, puesto que parte de un texto más breve (2011), luego desarrollado durante casi una década hasta convertirse en la edición reseñada aquí, y que continuó creciendo con la adición de ocho capítulos en la versión digital de Internet ${ }^{36}$. Es, sin duda, un proyecto diferente de los anteriores en su planteamiento editorial y gestación, al margen del mundo periodístico o universitario, pero enriquecedor en muchos aspectos, singularmente porque el autor da respuesta a un asunto que le suscitó su experiencia personal y a la que anteriormente aludí: las relaciones entre la izquierda y el movimiento LGTBIQ+ en los primeros años del posfranquismo (de nuevo activismo e historiografía, relato social y memoria individual, se entrecruzan ${ }^{37}$ ).

Figura 2. Cubiertas de los libros de Ramón Martínez y Brice Chamouleau, que, desde concepciones y propuestas muy diferentes, representan dos de las novedades más significativas en la reciente historiografía LGTBIQ+
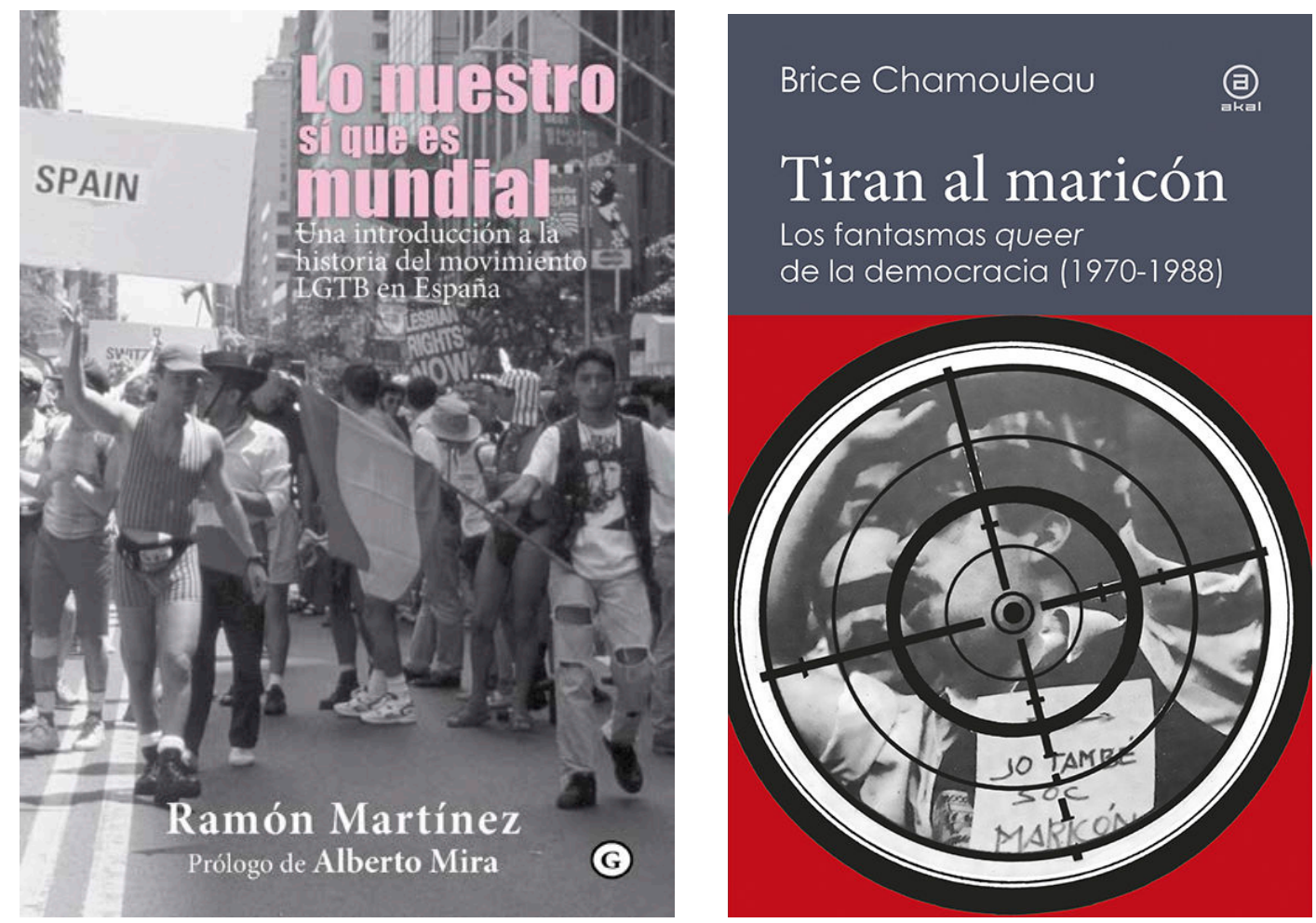

Aunque se inicia con el Sexenio Revolucionario y contiene análisis del discurso obrero decimonónico y del primer tercio del XX, realmente cobra mayor interés en los capítulos dedicados a la Transición en los que se evidencia que las organizaciones marxistas, libertarias u obreras no fueron necesariamente receptivas con la agenda del movimiento

35 P. Subrat, Invertidos y rompepatrias. Marxismo, anarquismo y desobediencia sexual y de género en el Estado Español (1868-1982), Madrid, El Imperdible, 2019, 576 pp.

36 Respectivamente P. Subrat, Invertidos y rompepatrias. Socialismo y homosexualidad en el estado español, Algorta, Distri Maligna, 2011, 198 pp. (firmado como C. Piro) y https://invertidosyrompepatrias.noblogs.org/ post/2019/08/16/libro-completo/

37 P. Subrat, Invertidos y rompepatrias. Marxismo..., p. 553. 
homosexual y mostraron escasa comprensión del hecho diferencial, cuando no llegaron a actitudes inconfundiblemente homófobas. Los casos de Tierno Galván (Partido Socialista Popular) y Eladio García Castro (Partido del Trabajo Español) pueden ser ilustrativos de declaraciones ásperas, pero en el otro lado de la balanza se deben citar la Liga Comunista Revolucionaria y la Organización Comunista de España-Bandera Roja, declaradamente homófilas. Con su enorme detalle — torrencial en ocasiones- estos capítulos son también un repaso del complejo puzzle de las izquierdas durante el arranque de la Transición.

No es baladí que entre las 600 páginas de este libro se dedique un capítulo al "fet sexual diferencial català", puesto que fue en Barcelona donde empezó el fenómeno reivindicativo como ya se ha indicado, pero que el autor amplía al País Valenciano, gracias especialmente a la investigación de Pau López Clavel. Su tesis doctoral merece desde luego alguna valoración, aunque no se pueda considerar en sentido estricto una novedad editorial todavía. En El rosa en la senyera ${ }^{38}$ Clavel desarrolla una rigurosa investigación sobre el movimiento en Valencia entre 1976 y 1997. A partir de fuentes tanto orales como escritas y con las deudas teóricas del giro queer y la historiografía de los nuevos movimientos sociales, despliega una perspectiva descentralizada que no se circunscribe al ámbito asociativo más formalizado (Lambda), sino que incorpora otras subjetividades como la trans, sin olvidar la fuerte presencia lesbiana en organizaciones mixtas y propias. El balance es claro en cuanto a la estrategia pragmática que el movimiento adoptó en Valencia, al tratar de incidir en las instituciones de gobierno local, e, igualmente, por lo que se refiere a su aportación social como agente democratizador relevante para alcanzar un sistema político más inclusivo ${ }^{39}$.

El último trabajo sobre el que me detendré es el reciente volumen colectivo preparado por Víctor Mora y Geoffroy Huard, 40 años después ${ }^{40}$. El libro surge como continuación de un encuentro celebrado anteriormente sobre la despenalización de la homosexualidad, que pretendía no solamente recordar el aniversario, sino ahondar en su conocimiento. Aúna dos tipos de contribuciones muy diferentes. Por un lado, los resultados de las investigaciones acometidas, por otro, los testimonios rescatados a partir de los cuales se construyen relatos breves para configurar una especie de "pequeña colección de cuentos de memorias de la disidencia sexual y de género" ${ }^{41}$.Veinte colaboraciones, en cuatro bloques, que firman algunos autores ya citados, como Huard (ruta histórica de las normas legales y la "lenta reparación" que se ha hecho a las víctimas, también simbólica, sobre la cual queda tarea pendiente), Javier Ugarte (génesis, evolución y uso de los conceptos de homosexual, invertido, marica...), o Raquel Osborne (quien nos habla del proyecto de investigación "mujeres bajo sospecha" para resituar a las mujeres lesbianas, ninguneadas y silenciadas por la dictadura). Es clara, pues, la concepción historiográfica del volumen, que pivota sobre los perfiles represivos de la dictadura, su afán controlador o el contexto de la historia comparada (el texto de Francisco Molina revela las confluencias de tratamiento con la dictadura portuguesa, fundamentalmente desde el discurso). Además, hay otra línea

38 P. López Clavel, El rosa en la senyera. El movimiento gay, lesbiano y trans valenciano en su perigeo (1976-1997), València, Universitat, 2018, 534 pp., tesis doctoral inédita en enero de 2020.

39 Ibídem, pp. 485 y ss., especialmente 498 y 503.

40 V. Mora y G. Huards (eds.), 40 años después. La despenalización de la homosexualidad en España, Barcelona-Madrid, 2019, 301 pp. Cuando redacto estas líneas ve la luz una interesante aportación desde la periferia geográfica. Se trata de V. M. Ramírez, Peligrosas y revolucionarias. Las disidencias sexuales en Canarias durante el franquismo y la Transición, Las Palmas de Gran Canaria, Fundación Tamaimos, 2019, 388 pp. La premura de tiempo impide su análisis, pero dejo constancia del trabajo. El autor había anticipado "Pioneros del movimiento homosexual en Canarias durante la transición", en Las otras protagonistas de la Transición. Izquierda radical y movilizaciones sociales, Madrid, Brumaria, 2018, pp. 97-110.

41 V. Mora y G. Huard (eds.), 40 años después..., p. 14. 
que aborda la necesidad de preservar el archivo LGTBIQ+ y de abrazar en su contenido heurístico todo tipo de fuentes (son las reflexiones de Javier Fernández-Galeano, Cecilia Montagut, Julen Zabala o Gracia Trujillo), aunque la denominación de "contra archivo" de resabios derridianos - me parece confusa e innecesaria para referirse a materiales efímeros y fuentes subjetivas. Del marco legal y las omisiones de la amnistía se ocupan Marina Echevarría y Roldán Jimeno.

Labibliografía sobre el movimiento es más extensa de lo que se ha recogido en las páginas precedentes, que solo reflejan las principales novedades librarias, pero he omitido, por razones de espacio, un buen puñado de capítulos de libros o artículos en revistas que tienen, sin duda, su interés ${ }^{42}$. Propongo ahora un giro en el enfoque y lo hago a partir de un reciente relato visual sobre la historia del movimiento, que a la vez es también todo un ejercicio historiográfico.

\section{NOSOTRXS SOMOS, EL RELATO TELEVISIVO SOBRE EL MOVIMIENTO ${ }^{43}$}

Empecemos por el título: "Nosotrxs somos" es una cita de la pancarta que encabezó aquella manifestación de Barcelona en junio de 1977. Inmortalizada por la cámara de Isabel Steva (Colita), allí se podía leer "Nosaltres no tenim por. Nosaltres som", sin género en catalán. Su traducción al castellano lo convertía en un lema masculinizado, pero persuadidos por las compañeras del equipo de producción, se sustituyó la "o" por la "equis"; un gesto de indudable reafirmación feminista, más allá de su corrección o incorrección gramatical: "El lenguaje también puede trasvertiste", afirma Paco Tomás, uno de los guionistas (cap. 7, 31'21") ${ }^{44}$. Fue realizada por Televisión Española en 2018 para su plataforma digital playz, un canal destinado al público joven que solo sirve contenidos gratuitos por Internet. El primer capítulo se emitió el 4 de julio y, a partir del 27 de mayo de 2019, se pasó también por La ${ }^{45}$. Detrás del proyecto está un equipo de periodistas de la entidad pública, dirigidos por César Vallejo e integrado por Paco Tomás, Rafael Lobo (guionistas) y Bárbara Mateos (realización) ${ }^{46}$.

42 Como muestra de valiosos estudios regionales, ver también R. López Romo, Del guetto a la calle. El movimiento gay y lesbiano en el País Vasco y Navarra, 1975-1983, San Sebastián, Tercera Prensa, 2008, 208 pp. (quien aborda tanto lo asociativo -EHGAM — como las subculturas gais); y "Una identidad emergente. El surgimiento del movimiento gay en el País Vasco de la Transición" en G. Capellán, R. Germán y J. Pérez (coords.), Historia social, movimientos sociales y ciudadanía, Logroño, Instituto de Estudios Riojanos, 2011, pp. 343-364.

43 Debo agradecer la información que me ha proporcionado para elaborar esta parte del texto el coguionista de la serie, Rafael Lobo Hernández, con quien mantuve una extensa entrevista personal (Madrid, 20-122019). No fueron solo datos, esta charla me ayudó a comprender cabalmente el proyecto.

44 Cito con la indicación del número de capítulo y el minutaje. La explicación sobre el título es ofrecida por su director, César Vallejo, en el mismo capítulo, 31'28".

45 La serie se puede visualizar tanto en playz (http://www.rtve.es/playz/nosotrxs-somos/) como en YouTube (https://www.youtube.com/playlist?list=PLc6y_blejLFEYtXHBxsDRuTIYAvk5yOrj). Ficha técnica en https:// www.filmaffinity.com/es/film929004.html. La noticia del estreno en la web corporativa (http://www.rtve.es/ rtve/20180704/playz-estrena-nosotrxs-somos-primera-serie-documental-sobre-lucha-del-colectivo-lgtbiespana/1759828.shtml) y su salto a La 2 en El Periódico, 24-5-2019 (https://www.elperiodico.com/es/ yotele/20190524/nosotros-somxs-rtve-2-javis-Igtbi-zapatero-7472329). A través de Twitter, se siguió con la etiqueta \#80mesoygay.

46 César Vallejo es editor digital de La 2 Noticias (http://www.rtve.es/rtve/20181107/2-noticias-vuelvemayor-presencia-digital-mantiene-su-apuesta-informar-forma-diferente/1834101.shtml), Paco Tomás dirige y presenta Wisteria Lane en Radio 5, programa dedicado al mundo LGTBIQ+ (https://musaquontas.wordpress. com), Rafael Lobo trabaja en los Servicios Informativos de TVE (Telediario 2) y Bárbara Mateos realizó en 2015 su primer largometraje documental, $A d$ ventun (http://adventumfilms.com/spanish.html). 
La inspiración para el proyecto procede de la serie norteamericana When we rise, un docudrama en ocho entregas estrenado por la cadena ABC que narra la historia del activismo en San Francisco entre 1970 y 2015 de la mano de uno de sus líderes, Cleve Jones, cuyas memorias sirvieron de base al guion ${ }^{47}$. Pero ¿por qué hacer un producto dramatizado si estaban vivos casi todos los protagonistas del activismo español? Así pues, la idea cristalizó en un proyecto documental, cuyo rodaje empezó en septiembre de 2017 y se simultaneó después con la emisión de episodios ya realizados, algo que les permitió a sus creadores ir teniendo retorno directo sobre su impacto ${ }^{48}$. Pero no podía tratarse simplemente de acumular horas de informativo, había que acercarse a los jóvenes que presumiblemente desconocían las luchas políticas de décadas anteriores. El resultado es un producto nítidamente intergeneracional, alejado de cualquier balance moral sobre el compromiso de una determinada generación y la supuesta indiferencia de otra; la primera estuvo en las calles, la segunda participa ahora comprendiendo la lucha desde las pantallas digitales e implicándose en enriquecer los logros con nuevas categorías. Es lo que Rafael Lobo define como una "victoria social con acompañamiento"49.

Para alcanzar ese objetivo sus creadores diseñaron una serie con siete capítulos de unos cuarenta y cinco minutos de duración que casan con los seis colores de la bandera icónica del movimiento, más un séptimo de mayor duración y planteamiento diferente, titulado precisamente "Arcoíris". Los seis principales descansan sobre una misma estructura narrativa. Se establece un diálogo abierto entre dos activistas del movimiento procedentes de generaciones diferentes que charlan de manera fluida entre ellos. A través de esa conversación se comprende el discurrir histórico del movimiento que atiende al doble eje, cronológico y temático, combinados en cada entrega. Las entrevistas se han rodado en lugares ligados a ese mismo devenir, como la prisión de Badajoz, hoy Museo Extremeño e Iberoamericano de Arte. Tienen una soberbia fotografía, gracias al trabajo de Pedro Fernández, a base de planos desaforados que sugieren la pequeñez del entrevistado frente a la grandeza visual del espacio que lo envuelve. El contraste entre ambas tomas subraya la emoción de quien habla, con sus gestos y su rostro ${ }^{50}$.

Alternan con esas entrevistas los testimonios de personas ligadas a diversos colectivos y las de asesores que enriquecen el discurso, entre los que cabe citar nombres ya conocidos: Víctor Mora, Gracia Trujillo, Fefa Vila, Kerman Calvo y Ramón Martínez. Se prescinde de la voz en off para la narración, aunque sí aparecen otros recursos como las infografías explicativas, la proyección de imágenes fijas o la inserción de vídeos procedentes del riquísimo fondo de TVE y otras filmotecas ${ }^{51}$. Esta recuperación de viejas grabaciones aporta un extraordinario valor documental en sí mismo, para lo que ha sido precisa una concienzuda labor de investigación por parte del equipo. Sirvan como ejemplo los minutos iniciales del capítulo 5 en los que una jovencísima Carla Antonelli hace de reportera callejera para el programa "Entre dos luces" (TVE, 1981) y a golpe de "canutazo" interroga a los madrileños sobre la transexualidad; o las imágenes de la seminal manifestación de Barcelona, en esta ocasión procedentes de una colección particular, en las que los personajes de la fotografía de Colita cobran vida. Impactantes son las respuestas que los viandantes dan al reportero

47 Ver la ficha https://www. filmaffinity.com/es/film492934.html y la noticia en Variety, 21-12-2015, https://variety. com/2015/tv/news/when-we-rise-abc-gay-rights-movement-gus-van-sant-dustin-lance-black-1201666289/.

48 Rafael Lobo, 20-12-2019, entrevista personal. Ver también el reportaje de Pablo León para El País, 7-72018: https://elpais.com/cultura/2018/07/06/television/1530895100_145502.html.

49 Rafael Lobo, 20-12-2019, entrevista personal.

50 Por supuesto no es algo casual, sino el resultado de un plan diseñado, como indica Rafael Lobo. Ibídem.

51 Casal Lambda Barcelona, COGAM, FELGTB, EGHAM, Lambda Valencia, MACBA y Museo Reina Sofía. 
de "Informe Semanal" (1983), cargadas de hostilidad en una fecha tan avanzada de la Transición y que dirigen sus dardos hacia la idea misma de un "orgullo gay", al que enfrentan el estrambote de un "orgullo machote"52.

No quisiera que detrás de la significación que estoy dando a la imagen se ocultara la importancia de la palabra. Realmente, se puede hablar de un ejercicio práctico de historia oral sobre cuya idoneidad para la historia presente caben pocas dudas ${ }^{53}$. Obviamente, no es un estudio de campo como el de un antropólogo o un experto en la Transición, pero la aportación consiste en recoger los testimonios de personas que no tardarán en desaparecer por pura lógica biológica y organizarlas con la coherencia de un discurso narrativo. Creo que, en este sentido, la serie tiene un valor incontestable, aunque los criterios de selección siempre puedan discutirse.

A propósito de todo ello, es pertinente recuperar el asunto del inexistente archivo LGTBIQ+ y desde aquí debo subrayar la necesidad de preservar un patrimonio documental quizás abocado a su desaparición. El coguionista de la serie, Rafael Lobo, reflexionaba sobre la cuestión en la entrevista de referencia y coincido con él. Fotografías, publicaciones de ínfima tirada, flyers, pegatinas, pancartas... y otros materiales efímeros están dispersos entre fondos públicos y colecciones particulares ${ }^{54}$. Lo relevante no es la dispersión, frecuente en tantas otras fuentes históricas, sino la conciencia sobre su necesaria preservación.

Antes de darle al play y recorrer brevemente los capítulos, quizás convenga proporcionar algunas cifras sobre una variable fundamental para el medio, las audiencias. No existen registros para la plataforma digital en la que se estrenó, pero sí hay algunos datos sobre la emisión en La 2 de TVE. El estreno de la serie reunió a 187000 espectadores (1,2 \% de cuota de pantalla). En su segundo capítulo, un 1,8\% (193000 televidentes). Habría que sumar las reproducciones en YouTube, con una métrica diferente y que oscilan entre los 5.476 del capítulo séptimo y los 2.106 del tercero ${ }^{55}$. Como se ve, cifras discretas, pero que ya las quisiéramos para algunos libros de historia.

Arranca la serie con el capítulo "Amarillo. Peligrosos y enfermos", articulado a partir del diálogo entre Antonio Ruiz (recluido por homosexual en la prisión de Badajoz, 1976) y Alejandro P. E. (transexual masculino y youtuber) ${ }^{56}$. El contraste generacional es tan

52 Antonelli en cap. 5, 00'09"; manifestación en cap. 1, 40'42"; e Informe Semanal en cap. 1, 28'42" y 35'26". 53 No es este el lugar para entrar en la cuestión, pero deben recordarse trabajos pioneros en España como C. Borderías "La Historia Oral en España a mediados de los noventa", Historia y Fuente Oral, 13 (1995), pp. 113-129; R. Fraser, Recuérdalo tú y recuérdalo a otros. Historia oral de la guerra civil española, Barcelona, Crítica, 2001; M. Vilanova "El combate en España, por una historia sin adjetivos con fuentes orales", Historia y Fuentes Orales, 14 (1995), pp. 95-116. O, más recientemente, M. Llona (ed.), Entreverse. Teoría y metodología práctica de las fuentes orales, Bilbao, UPV, 2012, 244 pp., con aportaciones de M. Vilanova y P. Díaz, además de la propia editora.

54 Rafael Lobo, 20-12-2019, entrevista personal. El Museo del Prado presentaba en diciembre de 2019 su colección de materiales ephemera: https://www.museodelprado.es/el-prado-efimero/la-historia-del-museoimpresa-en-papel. La Biblioteca Nacional de España ya lo había hecho en 2003 con una exposición y su catálogo: Ephemera: la vida sobre papel. Colección de la Biblioteca Nacional, BNE, Madrid.

55 Respectivamente, http://vertele.eldiario.es/audiencias-canales/analisis-espana/audiencias-lunes27mayolaotramirada-la1-tve-estreno-temporada-2_0_2125887392.html; http://vertele.eldiario.es/audienciascanales/analisis-espana/audiencias-lunes3junio-cinco-ofertas-dos-puntos-prime-time-lunes-horasbajas_0_2127987182.html. Tomo las cifras de YouTube del propio canal de TVE (21-12-2019).

56 Antonio Ruiz recibió en 2009 cuatro mil euros de indemnización estatal por su reclusión en prisión. Alejandro P. E. cuenta con más de 66.000 suscritores en su canal de YouTube. I. F. Lantigua, "Antoni, sólo 4.000 euros tras estar preso por ser homosexual" en El Mundo, 3-1-2017, https://www.elmundo.es/socied ad/2017/01/03/586a9f5f468aeb321b8b464a.html; https://www.youtube.com/channel/UCl8CHK7bRmKHuYaMOfq39Q. 
elocuente como la capacidad de mutua empatía que demuestran los protagonistas a la hora de conducirnos por los años finales del franquismo. También participan, entre otros, Mar Cambrollé y Armand de Fluviá, que nos ayudan a conocer los orígenes del movimiento en España. Es un repaso soberbio por la represión policial y judicial contra los homosexuales, conjugado con la aparición de los primeros núcleos asociativos ${ }^{57}$.

Figura 3. Armand de Fluviá entrevistado en el capítulo 2, 11'40"

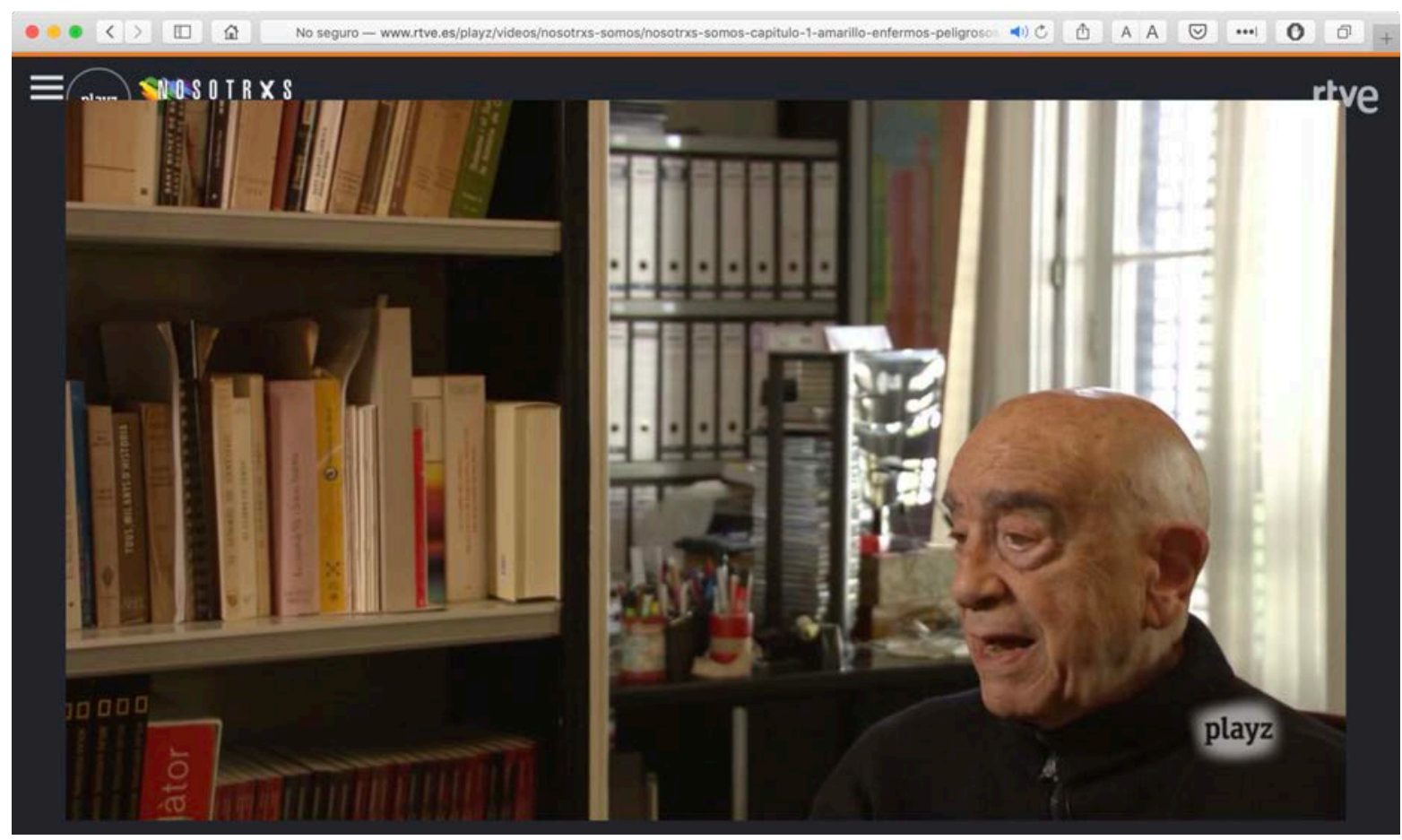

Fuente: captura de pantalla de la emisión en playz (www.rtve.es/playz/)

En el segundo capítulo, "Verde. El camino a la igualdad", se amplía el espectro sociológico a personas de género no binario. Así se definía, antes de iniciar su transición, Jedet, joven artista que dialoga con Jordi Petit sobre visibilidad y normatividad para ilustrar una etapa más madura del movimiento, con hitos asociativos como la fundación de la Coordinadora de Frentes de Liberación Homosexual del Estado Español o el Instituto Lambda. Pero el ímpetu reivindicativo también tuvo su reverso en la despolitización de un sector del colectivo, más relajado y visible gracias a la creciente oferta del ocio nocturno gay, singularmente en Madrid. El barrio de Chueca se conceptúa como un espacio de cohesión, seguridad y presencia social, aun cuando se deslizan tenues críticas acerca de la orientación marcadamente masculina del entorno y su inconfundible monetarización: "barrios que nos protegen y donde nos sacan el dinero también" (Kerman Calvo, cap. 2, 37'17').

Mas la mayor visibilidad y el crecimiento asociativo, no exento de polémicas escisiones, se vieron brutalmente sacudidos por la aparición del SIDA, al que se dedica el tercer capítulo, "Rojo. El revés de lo imprevisto". Son los minutos más emotivos del proyecto, en los que no falta la perspectiva histórica y su análisis: "EI SIDA activó otra vez la alianza entre gais y lesbianas", afirma Gracia Trujillo (cap. 3, 13'41"), tras el distanciamiento

57 No puede obviarse la existencia de dos documentales sobre la represión del franquismo: Los armarios de la dictadura, 2003, un proyecto colectivo surgido en el seno de un Máster de la Autónoma de Barcelona (http:// expresos-sociales.blogspot.com/2007/03/los-armarios-de-la-dictadura.html) y Pero que todos sepan que no he muerto, dirigido por A. Weiss en 2017 (https://www.filmaffinity.com/es/film278342.html), nominada a mejor filme documental en el Festival de Berlín de 2017. 
de género que se había vivido a principios de los ochenta. Esta cuestión, así como el debate entre igualitaristas y comunitaristas, está bien resuelta en pantalla. La Radical Gai, COGAM, Fundación Triángulo... materializaron dichos debates.

Llegamos al ecuador de la serie con el momento cumbre en materia de legislación igualitaria, es decir, la aprobación del matrimonio homosexual en 2005, presentado históricamente en clave de presión, negociación y logro en "Azul. Un país más decente". El subtítulo procede de las palabras del expresidente del gobierno, Rodríguez Zapatero, entrevistado por Javier Ambrosi y Javier Calvo, los "Javis". De nuevo, el cruce generacional, referentes mileniales frente a un representante de la "vieja" política postransicional ${ }^{58}$. Interesa subrayar la minuciosidad con la que se plasma todo el proceso y sus diversas ramificaciones, como la campaña del "Vota rosa" y el recurso de inconstitucionalidad presentado por el PP. El capítulo explica la reforma legal por la combinación de movilización ciudadana, influencia de activistas en los dirigentes políticos (Pedro Zerolo) y decisión de la propia elite, cuya labor reconoce. En el metraje se suman, entre otras voces, las de Alfonso Llopart (revista Shangay) y Jesús Generelo (FELGTB).

Figura 4. Pasquín del Frente de Liberación Homosexual de Castilla (FLHOC), mostrado en el capítulo 2, 5'12"

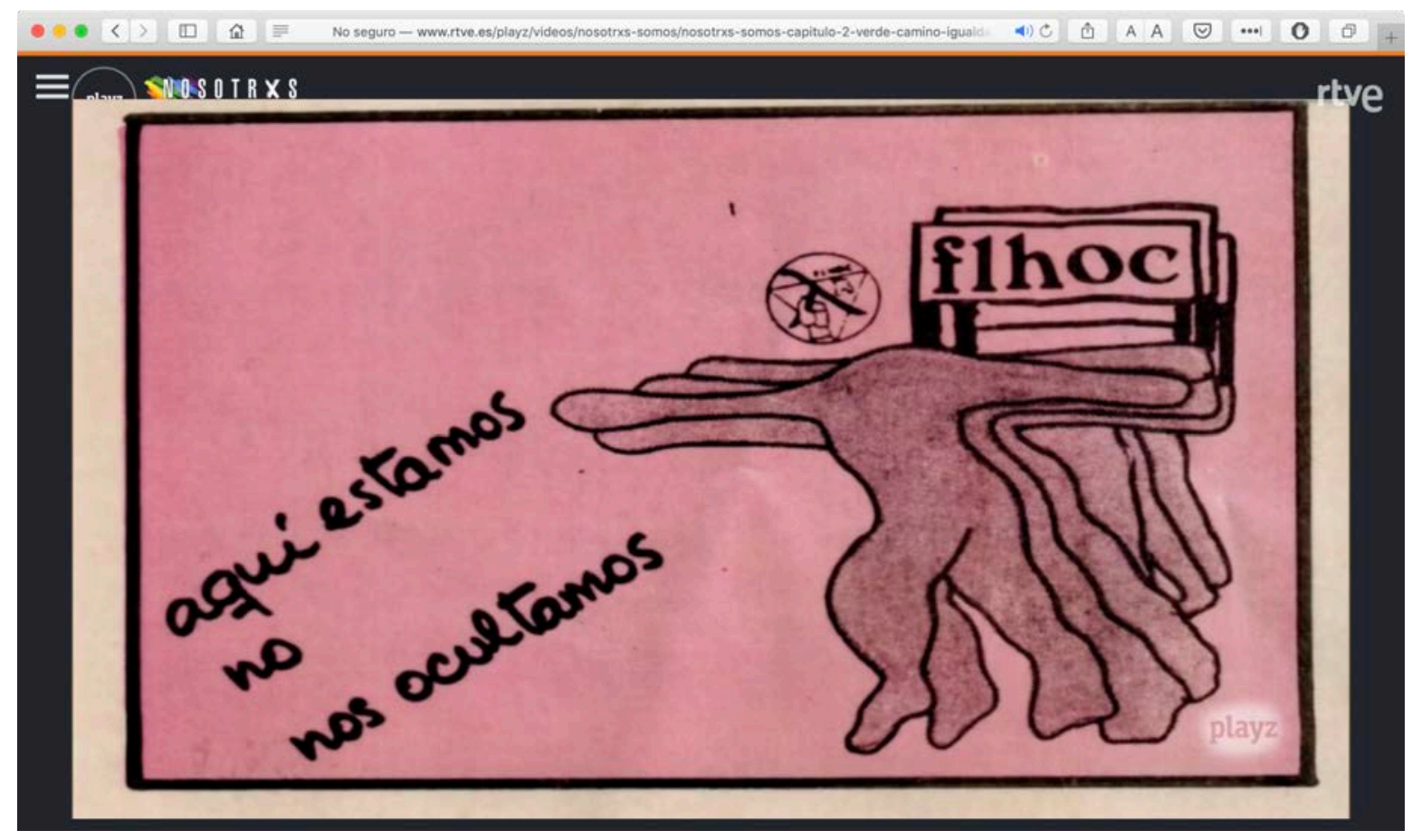

Fuente: captura de pantalla de la emisión en playz (www.rtve.es/playz/)

Con la quinta entrega, la apuesta por la diversidad es firme. A pesar de que no se obvia la vinculación de muchas personas trans con el mundo sórdido de la prostitución y la marginalidad, el capítulo se articula a partir de la entrevista con una profesora de Ética, Kim Pérez, activista ya jubilada de las aulas, que proyecta una imagen de mayor

58 La entrevista, valiosa en sí como documento, tuvo cierto eco en medios digitales, como formulatv y shangay (25 y 26-6-2018, respectivamente). https://www.formulatv.com/noticias/zapatero-habla-los-javisnosotxs-somos-matrimonio-homosexual-mejores-93351/; $\quad$ https://shangay.com/2019/06/26/zapatero-sesincera-con-los-javis-sobre-el-matrimonio-homosexual/; y http://www.eltelevisero.com/2018/02/los-javis-sereunen-con-zapatero-para-abordar-la-lucha-lgtbi/. 
¿normalidad? Bien diferente es el relato que hace Silvia Reyes ${ }^{59}$ y que enriquece las subjetividades proyectadas en la pantalla, reforzadas acertadamente al incluir también la problemática de la transexualidad infantil. El hilo cronológico (pasos en la despatologización de la transexualidad y su normatividad legal) se combina con la perspectiva internacional. Puede recordarse que en España fue delito hasta 1983 la realización de las operaciones de cambio de sexo, a pesar de lo cual se hacían clandestinamente.

La presencia de las mujeres lesbianas es constante en toda la serie, pero además se le dedica el último capítulo temático, "Violeta. La revolución lesbiana", vertebrado con la charla de Dolors Majoral y el dúo Devermut ${ }^{60}$. Se habla de la confluencia inicial con los grupos gais y la participación en las primeras manifestaciones, su posterior salida de ese ámbito hacia el feminismo y el reencuentro entre ambos colectivos. Trayectoria que se comprende a la vez que se desgranan conceptos como el del lesbianismo separatista o el debate, nada nominalista, sobre si eran "feministas lesbianas" o "lesbianas feministas". En la agenda reivindicativa propia la custodia sobre los hijos (cuestionada por algunos jueces), la inseminación artificial en el sistema público de salud, la lucha constante por una visibilidad negada, las tensiones machistas en el seno del movimiento LGTBIQ+ y la bifobia. Participan Beatriz Gimeno y Boti García (nombradas en enero de 2020, respectivamente, directora del Instituto de la Mujer y responsable de Diversidad Sexual y LGTBI, Ministerio de Igualdad), así como de Mili Hernández (Librería Berkana), entre otras activistas. La recuperación del testimonio de Gretel Amman, ya fallecida, es posible gracias a la estupenda documentación videográfica.

Figura 5. Acción reivindicativa a favor del matrimonio igualitario en los juzgados de Madrid. 1995. Capítulo 4, 12'58"

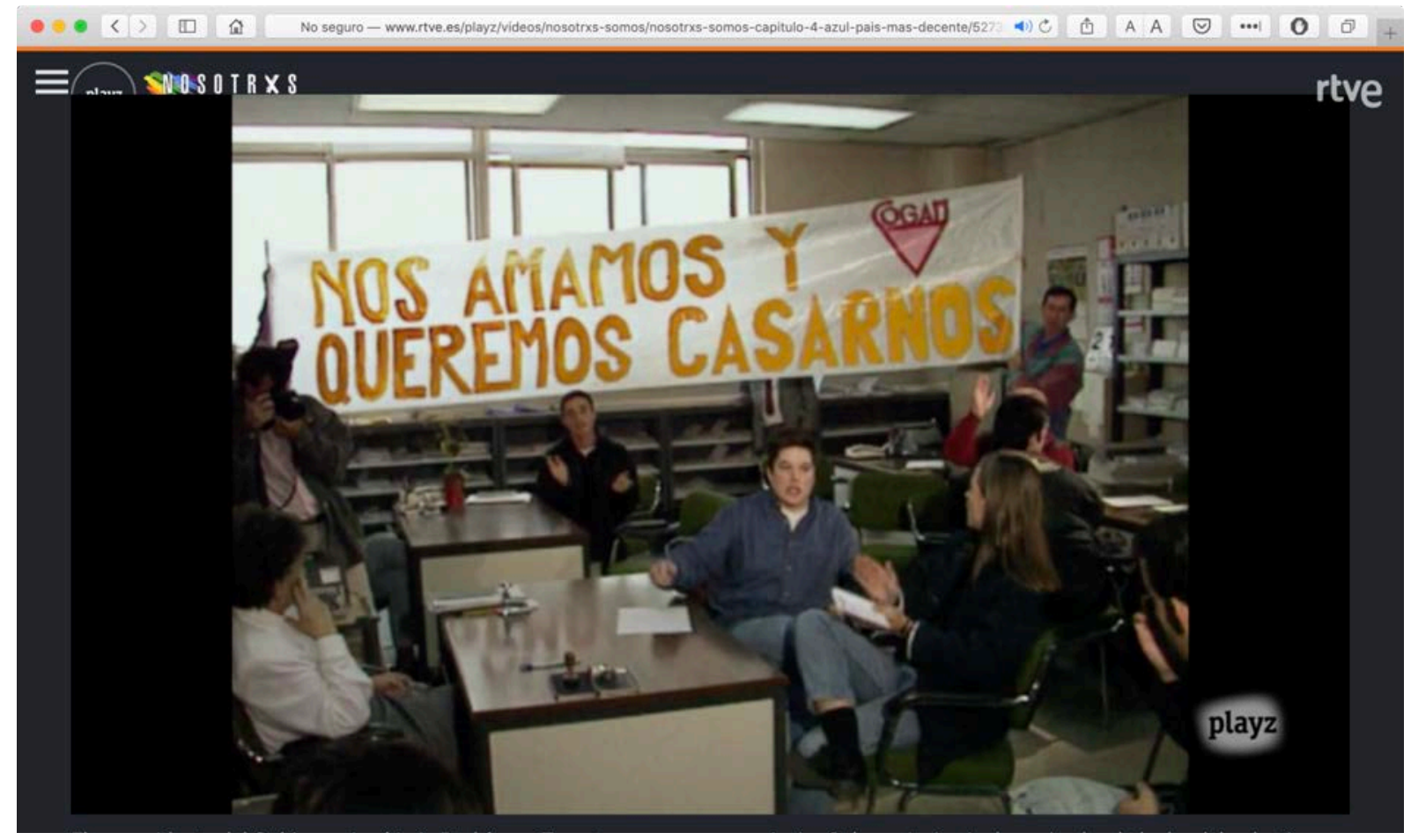

Fuente: captura de pantalla de la emisión en playz (www.rtve.es/playz/)

59 Ver la entrevista a Silvia Reyes en El Periódico (26-12-2018), dentro de la serie "Los rostros de la represión franquista". https://www.elperiodico.com/es/sociedad/20181226/las-transexuales-no-teniamos-otra-salidaque-la-prostitucion-7217596.

60 Dolors Majoral puso en marcha Daniel's, el primer pub nocturno exclusivamente para lesbianas en Barcelona. Sara y Marta integran Devermut, cuyo canal en YouTube cuenta con 322.000 seguidoras. 
Finalmente, "Arcoíris. Los retos del futuro", una entrega con un formato radicalmente diferente y más próximo al público objetivo de playz. Se trata de un magazín presentado por Marc Giró y Carolina Iglesias ${ }^{61}$ que se inicia con la actuación de Víctor Algora, el cantautor indie que firma el tema principal ${ }^{62}$. Bajo la apariencia de programa frívolo, deudor de la cultura pop (música, moda, creación...), se plantean de manera sencilla debates de calado o identidades en construcción, como la bisexualidad, el género fluido, la moda ungender y la preocupante violencia homófoba. Es decir, desde una perspectiva ricamente diversa, como el propio colectivo que refleja.

En suma, estamos ante una excelente serie de televisión que repasa la historia del movimiento LGTBIQ+ en España y recupera voces e imágenes de gran interés documental. Por su calidad ha ganado en 2019 el Premio Rey de España de Periodismo (categoría cultural y desarrollo social) y ha sido nominada a los GLAAD Awards ${ }^{63}$, pero además hay que considerarla una aportación relevante al estado historiográfico de la cuestión y un relato singular sobre la Transición, porque saca a la luz el papel político de un colectivo insuficientemente visibilizado en otros estudios sobre los nuevos movimientos sociales ${ }^{64}$. No es el lugar para entrar en el debate en torno a las tesis pesimistas y los efectos revisionistas que han tenido impacto reciente en las lecturas de la Transición (olvido culpable o democracia de baja calidad) ${ }^{65}$, pero sí se debe indicar que Nosotrxs somos se aleja de ese contexto interpretativo y subraya la consecución de conquistas legales fundamentales, si bien introduce una doble llamada de atención. Primero, en cuanto a la prolongación del posfranquismo para las personas LGTBIQ+ debido a la tardanza en derogar la Ley de Peligrosidad Social y a la aplicación discrecional del delito de escándalo público. Y, en segundo lugar, por la reivindicación de la memoria de esta parte de la población española, cuya restitución no parece haberse completado. Todo ello contribuye a resaltar la aportación hecha por gais, lesbianas y transexuales para construir una nación más justa, una democracia social más amplia. Nosotrxs somos no es solo un producto de televisión, sino una narrativa historiográfica, aunque las gramáticas de periodistas e historiadores a veces no sean las mismas.

61 Giró ha trabajado en Marie Claire, Tele 5, La Sexta y, últimamente, RAC1. Iglesias se vincula a YouTube, Los 40 Principales y TVE.

62 Letra y canción en https://genius.com/Algora-nosotrxs-somos-lyrics.

63 Los Premios Internacionales de Periodismo Rey de España son concedidos por EFE y la Agencia Española de Cooperación Internacional desde 1983 para reconocer la labor informativa de periodistas en lengua española y portuguesa. Por su parte, los GLAAD distinguen desde hace 31 años los mejores productos documentales y de entretenimiento sobre temática LGTIBQ+. Se pueden consultar sus respectivas webs oficiales: https://www.efe.com/efe/espana/sociedad/los-grandes-asuntos-sociales-triunfan-enpremios-rey-de-espana-periodismo/10004-4173801\# (fallo conocido en 14-2-2020) y https://www.glaad.org/ mediaawards/31/2020\%20nominees.

64 Aunque los objetivos y propuestas son muy diferentes, parece inevitable la comparación con La Transición, de E. de Andrés y V. Prego, TVE, 1995. Ver S. Alegre, "La Transición Española, un documental histórico", Filmhistoria online, 3 (2000), pp. 169-194.

65 La bibliografía es inmensa y hay voces más autorizadas que la mía al respecto. G. Alonso, "Lecturas de la Transición", en Reevaluaciones. Historias locales y miradas globales, Zaragoza, Institución Fernando el Católico, 2011, pp. 165-177; M. Ortiz, "Historiografía de la Transición", en La transición a la democracia en España. Historia y fuentes documentales, Guadalajara, Anabad CLM, 2004, pp. 223240; y, más recientemente, G. Pasamar, La Transición española a la democracia ayer y hoy. Memoria cultural, historiografía y política, Madrid, Marcial Pons, 2019, 416 (en especial cap. 4 y pp. 363 y ss.); P. Ysás y C. Molinero, La transición. Historia y relatos, Madrid, Siglo XXI, 2018, epub (sobre todo cap. VI). 
Figura 6. Carla Antonelli en una concentración a favor de la ley integral de transexualidad. 2006. Capítulo 5, 26'12"

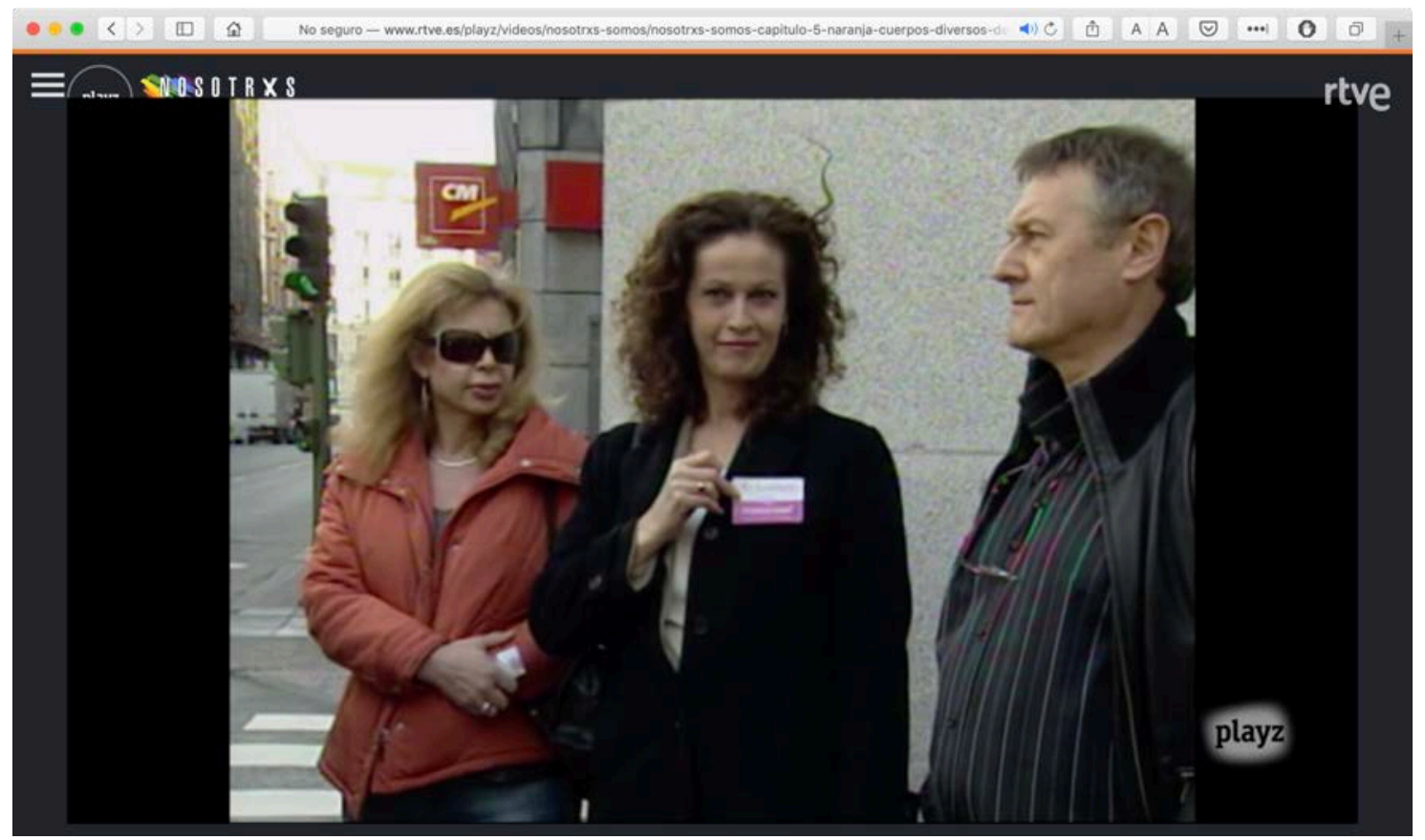

Fuente: captura de pantalla de la emisión en playz (www.rtve.es/playz/)

Con todo, alguna cuestión se ha echado en falta, quizás de difícil incorporación al producto televisivo por ausencia de documentación audiovisual, singularmente el silencio sobre una respuesta LGTBIQ+ en la España rural. La centralidad de Madrid, Barcelona o Valencia oculta otras vivencias. ¿Cómo explicar, por ejemplo, la existencia muy temprana de una oferta de ocio gay en La Mancha? En Tomelloso existió un bar destinado a este público del que surgió, primero la celebración de una fiesta del orgullo y, después, iniciativas asociativas y culturales que contribuyeron, sin duda, a la sociabilidad reivindicativa ${ }^{66}$. Es preciso que la historiografía aborde la descentralización de los estudios que ya se acometió hace décadas para otros asuntos.

Cierro este ensayo bibliográfico en los bordes de la historiografía más académica para deslizarme fuera de ellos con un gesto de memoria activista. Citar a estas alturas a Pierre Nora $^{67}$ es casi una obviedad de manual, pero son tan escasos los lugares de la memoria LGTBIQ+ en España que merece la pena reproducir una imagen del monumento contra la homofobia que se alza en Sitges, ciudad de la costa catalana que todavía es un referente para la comunidad gay, si es que la comunidad existe. Más allá del marco legislativo en el que tanto se ha avanzado, aun cuando está inconclusa la nueva ley integral, las organizaciones de nuestro país siguen denunciando constantemente ataques homófobos y tránsfobos, a veces físicamente violentos, brutales; otras, más sutiles y casi invisibles.

66 Ver P. Díaz, "XXV Aniversario Gay: de la Gran Manzana a La Corrala de Tomelloso", Bisagra, 333 (julio 1994), pp. 60-61; "Erotismo y literatura en el López Torres", El Periódico del Común de La Mancha, 91 (julio 1996), p. 28; y M. García, “La Corrala acogerá el sábado la Fiesta Orgullo'08”, Lanza, 26-6-2008, p. 27.

67 P. Nora (dir.), Les Lieux de mémoire, Paris, Gallimard, 1984-1992. 
Figura 7. Monumento inaugurado en el paseo marítimo de Sitges en 2006 que recuerda la paliza recibida por un homosexual diez años antes. El triángulo rosa invertido era la insignia que los gais debían lucir en los campos de concentración nazis. En el momento de la fotografía el espacio se colmaba con muestras de cariño por las víctimas del atentado de Orlando, 2016.

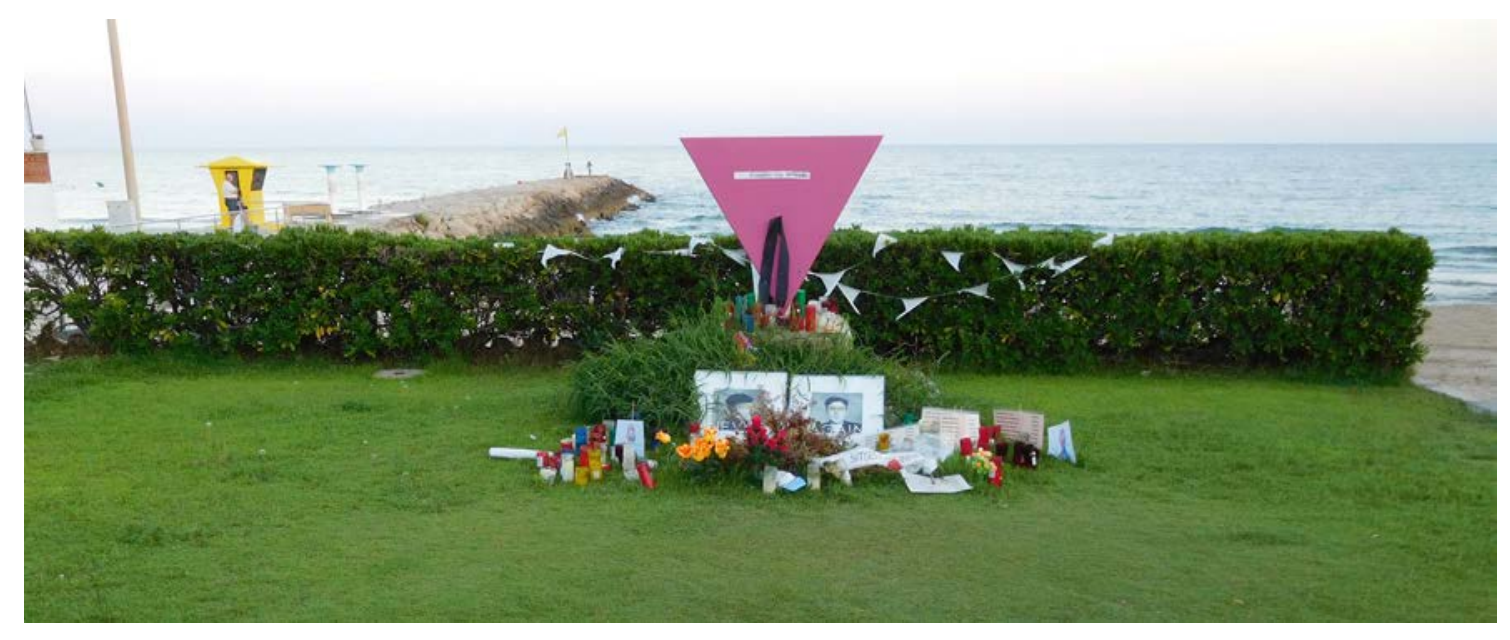

Fuente: Wikimedia CC.

\section{BIBLIOGRAFÍA}

ABC (2019): "«Mayores sin armarios» es el lema del Orgullo Gay 2019", https://www.abc. es/espana/abci-mayores-sin-armarios-lema-orgullo-2019-201907061548_video.html [enero 2020].

Ajuntament de Barcelona (2017): "Barcelona commemora el 40 aniversari de la primera manifestació LGTBI a la ciutat amb un programa anual d'activitats", https://ajuntament. barcelona.cat/premsa/2017/06/16/barcelona-commemora-el-40-aniversari-de-laprimera-manifestacio-Igtbi-a-la-ciutat-amb-un-programa-anual-dactivitats/ [enero 2020].

Alegre, S. (2000): “La Transición Española, un documental histórico", Filmhistoria online, 3, pp. 169-194.

Algora, V. (2018): Nosotros somos, Letra de la canción, https://genius.com/Algora-nosotrxssomos-lyrics [enero 2020].

Alonso, G. (2011): "Lecturas de la Transición", en Reevaluaciones. Historias locales y miradas globales, Zaragoza, Institución Fernando el Católico, pp. 165-177.

Armstrong, E. A. (2002): Fording gay identities: Organizing sexuality in San Francisco, 19501994, Chicago, Chicago University Press.

Armstrong, E. A. y S. M. Crage (2006): "Movements and Memory: The Making of the Stonewall Myth", American Sociological Review, 71, pp. 724-751.

Arnalte, A. (2003): Redada de violetas: la represión de los homosexuales durante el franquismo, Madrid, La Esfera de los Libros.

Baidez, N. (2007): Vagos, maleantes... y homosexuales: la represión a los homosexuales durante el franquismo, Barcelona, Malhivern.

Borderías, C. (1995): "La Historia Oral en España a mediados de los noventa", Historia y Fuente Oral, 13, pp. 113-129.

Bullough, V. L. (ed.) (2008): Before Stonewall: Activists for Gay and Lesbian Rights in Historical Context, New York, Routledge.

Calvo, K. (2017): ¿Revolución o reforma? La transformación de la identidad política del movimiento LGTB en España, 1970-2005, Madrid, CSIC. 
Chamouleau, B. (2017): Tiran al maricón. Los fantasmas queer de la democracia (19701988), Madrid, Akal.

Conde Duque Madrid (2017): "El porvenir de la revuelta", https://www.condeduquemadrid. es/sites/default/files/import/activities/2017/05/el-porvenir-de-la-revuelta-dossier_ abril_2017.pdf [enero 2020].

Córdoba, D. J. Sáez y P. Vidarte (2005): Teoría Queer. Políticas bolleras, maricas, trans, mestizas, Barcelona-Madrid, Egales.

Cuesta, J. (2019): "Zapatero reflexiona con Los Javis del matrimonio homosexual en «Nosotrxs Somos»", https://www.formulatv.com/noticias/zapatero-habla-los-javisnosotxs-somos-matrimonio-homosexual-mejores-93351/ [enero 2020].

Cuesta, J. (ed.) (1998): "Memoria e Historia", Ayer, 32, pp. 11-245.

Díaz-Guardiola, J. (2016): "«El porvenir de la revuelta»: la urgente necesidad LGTB de echar la mirada cuarenta años atrás", https://www.abc.es/cultura/cultural/ abci-porvenir-revuelta-urgente-necesidad-social-echar-mirada-cuarenta-anosatras-201705262129_noticia.html [enero 2020].

Díaz, P. (1994): "XXV Aniversario Gay: de la Gran Manzana a La Corrala de Tomelloso", Bisagra, 333, pp. 60-61.

EFE (2020): "Los grandes asuntos sociales triunfan en Premios Rey de España de Periodismo", https://www.efe.com/efe/espana/sociedad/los-grandes-asuntos-socialestriunfan-en-premios-rey-de-espana-periodismo/10004-4173801\# [enero2020]

El Mundo (2017): "2,3 millones de personas y 115 millones de gasto directo durante el WorldPride 2017", https://www.elmundo.es/madrid/2017/07/07/595f752eca4741976d 8b45c7.html [enero 2020].

El País (2019): Especial Orgullo Gay, https://elpais.com/tag/orgullo_gay/a [enero 2020].

El Periódico del Común (1996): "Erotismo y literatura en el López Torres", El Periódico del Común de La Mancha, 91, p. 28.

Facultad de Humanidades de Toledo (2019): "Un orgullo necesario. Algunos hitos históricos contra la homofobia", https://humanidadestoledo.uclm.es/exposicion-un-orgullonecesario-algunos-hitos-historicos-contra-la-homofobia/ [enero 2020].

Faderman, L. (2015): The Gay Revolution: The Story of the Struggle, New York, Simon \& Schuster.

FELGTB (2017): "Subversivas: que intentan subvertir el orden social o moral establecido", en https://www.felgtb.com/subversivas/exposicion/ [enero 2020].

Fernández, B. (2019): "Diccionario de diversidad sexual”, https://elpais.com/especiales/2019/ diccionario-diversidad-sexual/ [enero 2020]

Fluviá, A. de (2003): El moviment gai a la clandestinitat del franquisme (1970-1975), Barcelona, Laertes.

Fraser, F. (2001): Recuérdalo tú y recuérdalo a otros. Historia oral de la guerra civil española, Barcelona, Crítica.

Frouz, S. (2007): "Una historia propia: la memoria homosexual en España", Journal of Iberian and Latin American Studies, 13, 1, pp. 97-103.

Gálvez, S. (coord.) (2007): "Generaciones y memoria de la represión franquista: un balance de los movimientos por la memoria", Hispania Nova, 7, sp. http://hispanianova.rediris. es/7/dossier.htm [enero 2020].

García, H. (2019): "Zapatero se sincera Los Javis sobre el matrimonio homosexual", https:// shangay.com/2019/06/26/zapatero-se-sincera-con-los-javis-sobre-el-matrimoniohomosexual/ [enero 2020].

García, M. (2008): “La Corrala acogerá el sábado la Fiesta Orgullo’08”, Lanza, 26-6-2008, p. 27. 
GLAAD Awards (2020): "The Nominees for the 31st Annual GLAAD Media Awards", https:// www.glaad.org/mediaawards/31/2020\%20nominees [2020].

Huard, G. (2014): Los antisociales, Historia de la homosexualidad en Barcelona y París, 1945-1975, Madrid, Marcial Pons.

Huard, G. (2016): Les gays sous le franquisme. Discours, subcultures et revendications à Barcelone, 1939-1977, Paris, Éditions Orbis Terrius.

Lantigua, I. F. (2017): "Antoni, sólo 4.000 euros tras estar preso por ser homosexual" https:// www.elmundo.es/sociedad/2017/01/03/586a9f5f468aeb321b8b464a.html [enero 2020].

León, P. (2018): "Homosexualidad en tiempos revueltos", https://elpais.com/ cultura/2018/07/06/television/1530895100_145502.html [enero2020].

Llona, M. (ed.) (2012): Entreverse. Teoría y metodología práctica de las fuentes orales, Bilbao, UPV.

López Clavel, P. (2018): El rosa en la senyera. El movimiento gay, lesbiano y trans valenciano en su perigeo (1976-1997), València, Universitat.

López Romo, R. (2008): Del guetto a la calle. El movimiento gay y lesbiano en el País Vasco y Navarra, 1975-1983, San Sebastián, Tercera Prensa.

López Romo, R. (2011): "Una identidad emergente. El surgimiento del movimiento gay en el País Vasco de la Transición" en G. Capellán, R. Germán y J. Pérez (coords.), Historia social, movimientos sociales y ciudadanía, Logroño, Instituto de Estudios Riojanos, pp. 343-364.

Martínez, R. (2016): La cultura de la homofobia, Barcelona-Madrid, Egales.

Martínez, R. (2017): Lo nuestro sí que es mundial. Una introducción a la historia del movimiento LGTB en España, Barcelona-Madrid, Egales.

Martínez, R. (2019): Nos acechan todavía. Anotaciones para reactivar el movimiento LGTB, Barcelona-Madrid, Egales.

Martínez, Ricard(2019): "Arqueologíadelpuntdevist”, https://www.arqueologiadelpuntdevista. org/instalaciones/molt-amor-per-fer/ [enero 2020].

Mira, A. (1977): Para entendernos: diccionario de cultura homosexual, gay y lésbica, Barcelona, Ediciones de la Tempestad.

Mira, A. (2004): De Sodoma a Chueca: una historia cultural de la homosexualidad en España en el siglo $X X$, Barcelona-Madrid, Egales.

Monferrer, J. M. (2003): "La construcción de la protesta en el movimiento gay español: la Ley de Peligrosidad Social (1970) como factor precipitante de la acción colectiva", Reis: Revista española de investigaciones sociológicas, 102 (2003), pp. 171-204.

Mora, V. y G. Huards (eds.) (2019): 40 años después. La despenalización de la homosexualidad en España, Barcelona-Madrid, Egales.

Mora, V. (2016): Al margen de la naturaleza. La persecución de la homosexualidad durante el franquismo. Leyes, terapias y condenas, Barcelona, Debate, 2016.

Museo Reina Sofía (2017): “¿Archivo queer? Prácticas de una memoria disidente”, https:// www.museoreinasofia.es/actividades/archivo-queer-memoria-disidente [enero 2020].

Museo Reina Sofía (2018): “iPor una sexualidad libre!”, https://www.museoreinasofia.es/ actividades/sexualidad-libre [enero 2020].

New York Public Library (2019): "Love \& resistance. Stonewall 50", https://www.nypl.org/ stonewall50 [enero 2020].

Noain, I. (2019): "50 años de Stonewall, los disturbios en los nació el Orgullo", https://www. elperiodico.com/es/mas-periodico/20190622/50-anos-de-stonewall-el-dia-que-nacioel-gay-power-7514741 [enero 2020].

Nora, P. (dir.) (1984-1992): Les Lieux de mémoire, Paris, Gallimard, 1984-1992. 
Olmeda, F. (2004): El látigo y la pluma: homosexuales en la España de Franco, Madrid, Oberón.

Ortiz, M. (2004): "Historiografía de la Transición", en La transición a la democracia en España. Historia y fuentes documentales, Guadalajara, Anabad CLM, pp. 223240.

Osborne, R. (ed.) (2012): Mujeres bajo sospecha. Memoria y sexualidad, 1930-1980, Madrid, Editorial Fundamentos, 2012.

Pasamar, G. (2019): La Transición española a la democracia ayer y hoy. Memoria cultural, historiografía y política, Madrid, Marcial Pons.

Pérez Garzón, J. S. (2012): "Memoria e historia: reajustes y entendimientos críticos", Ayer, 86, pp. 249-261.

Pérez, B. (2018): "«Las transexuales no teníamos otra salida que la prostitución» Entrevista con Slvia Reyes", https://www.elperiodico.com/es/sociedad/20181226/lastransexuales-no-teniamos-otra-salida-que-la-prostitucion-7217596 [enero 2020].

Petit, J. (2003): 25 años más: una perspectiva sobre el pasado, el presente y futuro del movimiento de gays, lesbianas, bisexuales y transexuales, Barcelona, Icaria.

Petit, J. (2004): Vidas del arco iris: historias del ambiente, Barcelona, De Bolsillo, 2004.

Posada, L. (2014): "Teoría queer", Daimon. Revista Internacional de Filosofía, 63, pp. 147158.

Ramírez, V. M. (2018): "Pioneros del movimiento homosexual en Canarias durante la transición", en Las otras protagonistas de la Transición. Izquierda radical y movilizaciones sociales, Madrid, Brumaria, pp. 97-110.

Ramírez, V. M. (2019): Peligrosas y revolucionarias. Las disidencias sexuales en Canarias durante el franquismo y la Transición, Las Palmas de Gran Canaria, Fundación Tamaimos.

Sears, J. (2011): Behind the Mask of the Mattachine: The Hal Call Chronicles and the Early Movement for Homosexual Emancipation, New York, Routledge.

Sears, J. y M. Stein (2004): City Of Sisterly And Brotherly Loves: Lesbian And Gay Philadelphia, 1945-1972, Filadelfia, Temple University Press.

Soriano, M. A. (2006): La marginación homosexual en la España de la Transición, BarcelonaMadrid, Egales.

Subrat, P. (2011): Invertidos y rompepatrias. Socialismo y homosexualidad en el estado español, Algorta, Distri Maligna.

Subrat, P. (2019): Invertidos y rompepatrias. Marxismo, anarquismo y desobediencia sexual y de género en el Estado Español (1868-1982), Madrid, El Imperdible.

Ugarte, F. J. (ed.) (2008): Una discriminación universal: la homosexualidad bajo el franquismo y la Transición, Bacelona-Madrid, Egales.

Ugarte, F. J. (2005): Sin derramamiento de sangre. Un ensayo sobre la homosexualidad, Bacelona-Madrid, Egales.

Universidad Autónoma de Barcelona (2003): Los armarios de la dictadura, Documental, http://expresos-sociales.blogspot.com/2007/03/los-armarios-de-la-dictadura.html [2020]

Vallejo, C. (2018): Nosotrxs somos, Serie documental en 7 episodios, RTVE - playz. http:// www.rtve.es/playz/nosotrxs-somos/ [enero 2020].

Vázquez, F. (coord.) (2012): "Homosexualidades", Ayer, 87.

Vélez-Pelligrini, L. (2011): Sujetos de un contradiscurso. Una historia intelectual de la producción teórica gay, lesbiana y queer en España, Barcelona, Ediciones Bellaterra.

Vila, L. (2019): “¿Qué significan las siglas LGTBIQ+?, https://www.lavanguardia.com/vida/ junior-report/20190627/463124839887/lgbtiq-definiciones.html [enero 2020].

Vilanova, M. (1995): "El combate en España, por una historia sin adjetivos con fuentes 
orales", Historia y Fuentes Orales, 14, pp. 95-116.

Weiss, A. (2017): Pero que todos sepan que no he muerto, Documental, Jezebel Productions.

Ximénez, M. (20019): "50 años de Stonewall, el germen de la lucha LGTB", https://www. vogue.es/living/articulos/stonewall-50-aniversario-lucha-Igtb [enero 2020].

Ysás, P. y C. Molinero (2018): La transición. Historia y relatos, Madrid, Siglo XXI, 2018. 